\title{
Thermal-Electromagnetic Analysis of a Fault-Tolerant Dual Star Flux-Switching Permanent Magnet Motor for Critical Applications
}

\author{
G.J. LI, Student Member, IEEE, J. OJEDA, Member, IEEE, E. HOANG, M. GABSI, Member, IEEE \\ SATIE, ENS Cachan, CNRS, UniverSud, 61, av President Wilson, F-94230 Cachan, France \\ guangjin.li@satie.ens-cachan.fr
}

\begin{abstract}
This paper presents a fault-electromagnetic-thermal model of a fault-tolerant dual star Flux-Switching Permanent Magnet (FSPM) motor. The analytical results in terms of phase currents, rotor velocity and output torque are firstly calculated by a Simulink-MATLAB based fault (short-circuit) model. Then, the fault and normal phase currents are used in the motor 2D Finite Element Method (FEM) model to calculate the copper and iron losses. As the main heat sources in electrical machines, the obtained copper and iron losses are used in the Lumped Parameter $(L P)$ and the 3D FEM thermal models to calculate the temperatures of different machine components. Finally, the variation of temperatures of the machine in presence of faults can be predicted. The results obtained by the LP and the 3D FEM models are also validated by experimental tests. A good agreement has been observed among the analytical, numerical and experimental results. In order to realize the 3D FEM model of the doubly salient rotating machine, a method to transform the salient rotor into a non-salient one have been proposed. Some methods are also proposed to enhance the performance of the cooling system and decrease the maximum temperature of the machine.
\end{abstract}

Index Terms —Fault-tolerant, loss modeling, flux switching, thermal resistance network, finite-element method (FEM).

\section{INTRODUCTION}

DE to their high power density, the fault tolerant permanent magnet motors have attracted increasing attentions in safety critical applications such as Hybrid Electrical Vehicle (HEV) and more electrical aircraft. To enhance the fault tolerant capability, a lot of methods have been proposed in recent years, e.g. the multi-phase machines (the number of phase $n>3$ ) [1]-[5], multi-motor structures [6] or dual-star stator machines [7]-[8], etc. 
Concerning to multi-phase machines, due to their higher phase number, the power can be split across a greater number of inverter legs than classical three phase machines. As a result, the rating of the power devices could be relatively lower. Furthermore, the independent flux and torque control can be ensured even if one phase is open-circuited. This is impossible for the three-phase machines [1], [4]. However, the multi-phase machines need multiple inverter legs, and this non classical inverter structure could increase the cost of the system.

With regard to the multi-motor structures, the phases of the motors are magnetically and physically separated. Thus, the phase failures (short-circuit or open-circuit) of one motor will not infect the phases of other motors, and the rest machines can operate properly even in presence of faults in one motor. As a result, the reliability could be considerably increased. To some degree, this method is not suitable for the embedded systems as in aircraft and HEV, where the volume for installing the motors is often limited. However, because of the increase of additional end-winding length, the series [9] or parallel [6] motor connections need more system volume than the single-motor structure.

To obtain the advantages of both the foregoing structures, the dual star motors could be applied. In this paper, because of its high torque and power densities as well as its simple rotor structure, a dual star FluxSwitching Permanent Magnet (FSPM) motor is applied for controlling the Variable Stator Vane (VSV) of aircraft. In VSV application, the electrical machine is applied to control the open angle of vanes so that the air flow enters in the aircraft engine can be controlled and the regime of the engine can be regulated. The cross section of this dual star FSPM motor is shown in Fig. 1 (a), in which the stator and rotor tooth numbers are relatively 12 and 10. The rotor structure of the FSPM is as simple as that of Switched Reluctance Motors. Thus, the fault tolerance capability of this kind of machines can be significantly higher than rotor mounted permanent magnet machines [10]-[11]. For simplicity, we consider that the primary star consists of the phases $a, b$ and $c$, while the redundant one is composed by the phases $A, B$ and $C$. All the phase windings are concentrated. Thus, there is no overlapping contact between end-windings, and the end-winding length 
can be decreased. The two stars are supplied by two independent voltage source inverters (VSIs, see Fig. 2), and the neutral points of which are not connected together [7]-[8]. In healthy mode, only the primary star is supplied, which is similar to a classical three-phase permanent magnet motor. When a short-circuit or an open-circuit failure occurs, to decrease the torque pulsation and the mutual influence between phases, all the switches of the primary star are opened, and simultaneously, the redundant star is supplied. As a result, the operation continuity of the machine is ensured. A summary can be made that the dual star structure is similar to a double-motor structure (multi-motor). However, they are compacted into one entire motor structure as a six-phase (multi-phase), in which, only three phases are used. Thus, both the merits of the multi-motor and multi-phase structures can be taken into account by using the dual star structure.

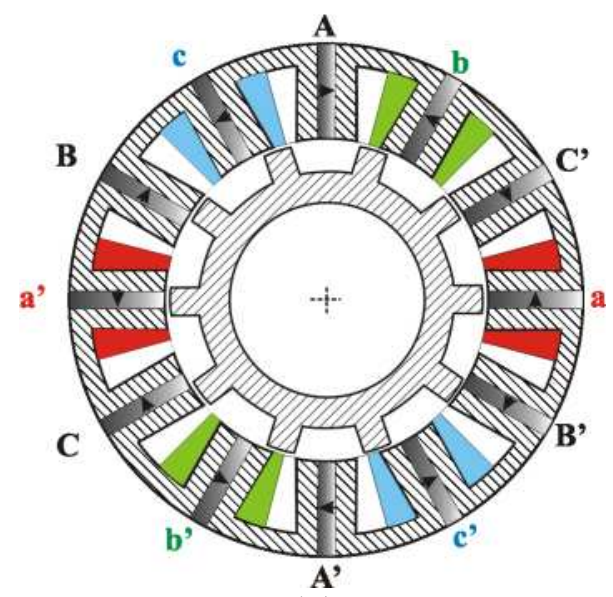

(a)

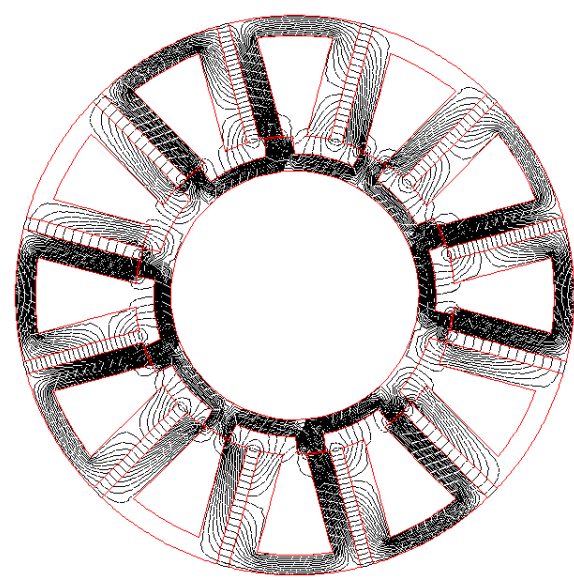

(b)

Fig. 1 Fault-tolerant dual-star flux-switching permanent magnet motor $(2 \times 6 / 10)$ that has two three phase stator windings. The phases $a, b$, c are primary phases, which are supplied during normal mode, while the phases $A, B, C$ are redundant phases supplied during fault regimes. (a) radial cross-section of the machine, (b) no-load flux distribution.

During the design process of a fault tolerant dual star FSPM motor, besides the fault tolerant consideration, the thermal problem caused by the faults should also be taken into account. Previous thermal modeling studies were often focused on the machine in normal mode, in which the main heat sources are the constant maximum copper, iron and mechanical losses [12]-[19]. A few studies have been reported about the electrical machines with driving cycles [20]-[22]. In this paper, due to the redundant phases, the open-circuit failure is not serious because it is sufficient to open all the phases of this star and to use the 
other one. However, for the short-circuit failures (especially for the terminal short-circuit of one phase), even if the switches of the inverter legs are opened, the short-circuit phases can always induce short-circuit current. This can produce a various resistant torque, which will disturb the output torque and the rotor speed. To maintain the same average output torque, the currents of the normal phases need to be increased to compensate this resistant torque. As a result, because of the presence of short-circuit current and the increase of normal phase currents, the copper and iron losses (the influence of mechanical losses are neglected) would be increased and the temperature could also increase considerably. This increase of temperature could exceed the thermal constraint, and the well designed motor in normal mode could not meet the machine specifications in fault mode. Thus, the main goal in this paper is to study the influence of short-circuit failures on the thermal behaviour of a dual star FSPM motor.

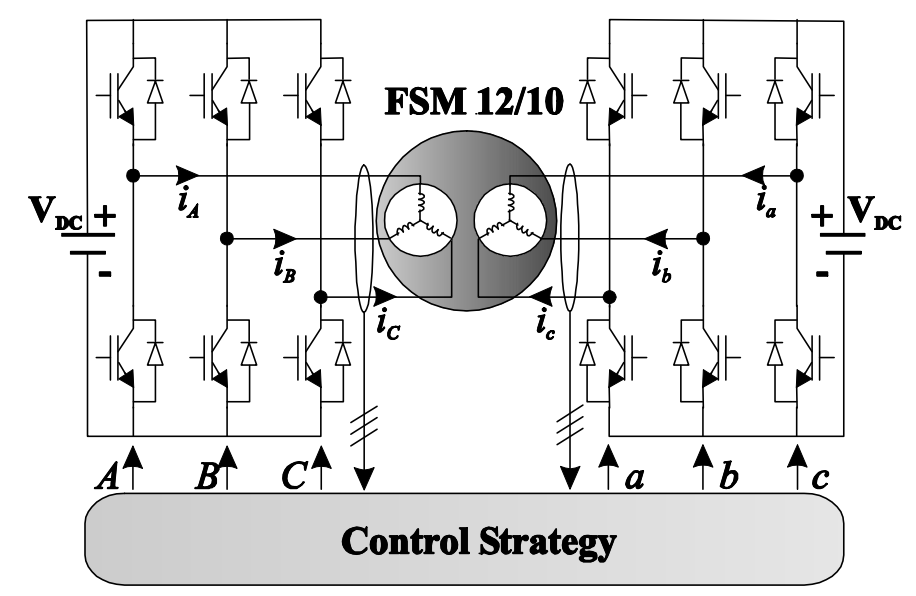

Fig. 2 Control scheme for fault tolerant dual star FSPM motor.

\section{Electromagnetic Model of Dual Star FSPM Motor}

\subsection{SHORT-CIRCUIT FAULT MODEL}

In this paper, the fault model is based on one phase terminal short-circuit of the primary star, which is shown in the Fig. 3. All the three phases of the primary star are opened, and the three phases of redundant star are then supplied simultaneously. As an example, the phase $a$ of the primary star is considered as short circuited. As been mentioned in previous section, even if the switch of the inverter leg of the short-circuit 
phase is opened, due to the permanent magnet and the self and mutual inductances, the short-circuit current can still appear.

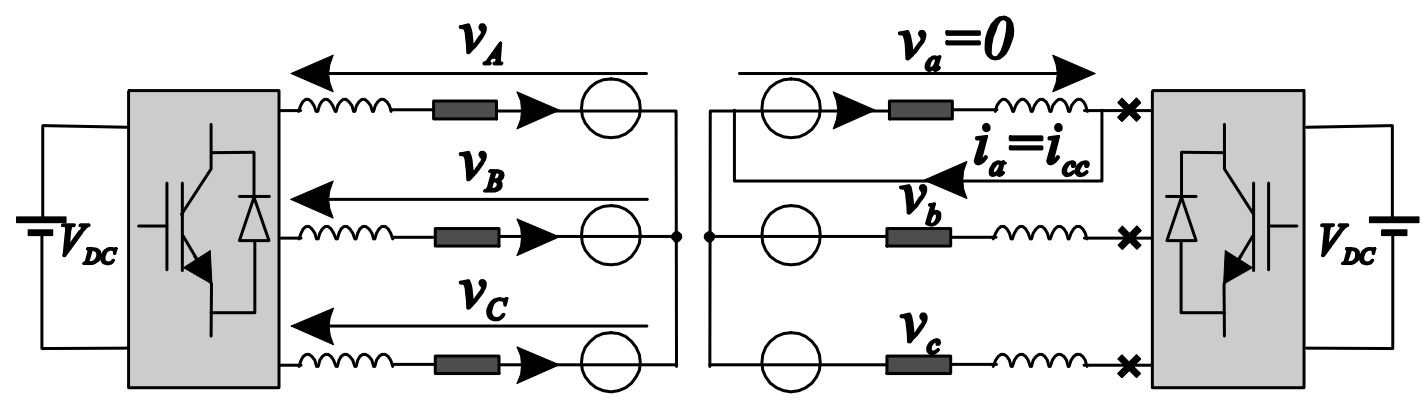

Fig. 3 Equivalent circuit of the fault-tolerant dual star FSPM motor with one phase of the primary star short-circuited.

The neutral points are isolated and inaccessible, the relation among the three redundant phase currents is:

$$
i_{A}+i_{B}+i_{C}=0
$$

Following generator convention, the relationship between the no-load electromotive force (EMF) of the short-circuit phase $a\left(e_{a}\right)$ due to the permanent magnets and the phase currents could be established as:

$$
e_{a}=\frac{d \Phi_{0}}{d t}=R_{a} i_{a}+L_{a} \frac{d i_{a}}{d t}+M_{a A} \frac{d i_{A}}{d t}+M_{a B} \frac{d i_{B}}{d t}+M_{a C} \frac{d i_{C}}{d t}
$$

Where

$$
\begin{array}{ll}
R_{a} \text { and } L_{a} & : \text { Resistance and self inductance of phase } a, \\
i_{a} & : \quad \text { Short-circuit current of phase } a, \\
\Phi_{0} & : \text { No-load phase flux linkage, }
\end{array}
$$

$M_{a A}, M_{a B}$ and $M_{a C} \quad: \quad$ Mutual inductance between phase $a$ and phase $A$, phase $B$ as well as phase $C$.

All the parameters of the (2) are calculated by 2D FEM and validated by experimental method. It is found that, if the high order harmonics are neglected, the EMFs of the corresponding phases between the primary and the redundant stars could be identical $\left(e_{a}=e_{A}\right)$. Furthermore, comparing to $M_{a B}$ and $M_{a C}\left(M_{a B}=M_{a C}\right)$, the $M_{a A}$ is significantly low. This is because the permanent magnets in the middle of the phases $B, C, b$ and $c$ form a natural barrier for the phase magnetic flux, which prevents the mutual flux created by the phase $a$ 
from passing through the phase $A$ via the stator yoke (see Fig. 1). As a result, the $M_{a A}$ is neglected. Without flux weakening operation, the expression of the short-circuit current in the phase $a$ can be written as:

$$
\begin{gathered}
i_{a}(t)=\left\{\frac{M I_{A}}{L_{a}\left(\omega^{2}+(1 / \tau)^{2}\right)}\left[\omega\left(\frac{1}{\tau}+\frac{E_{a}}{M I_{A}}\right) \cos (\omega t)+\left(\omega^{2}-\frac{E_{a}}{M I_{A} \tau}\right) \sin (\omega t)\right]\right. \\
\left.-\frac{M I_{A} \omega}{L_{a}\left(\omega^{2}+(1 / \tau)^{2}\right)}\left(\frac{1}{\tau}+\frac{E_{a}}{M I_{A}}\right) e^{-\frac{t}{\tau}}\right\}
\end{gathered}
$$

where $e_{a}(t)=E_{a} \cos (\omega t+\pi / 2), \quad M=M_{a B}=M_{a C}, i_{A}(t)=I_{A} \cos (\omega t+\pi / 2), \tau=L_{a} / R_{a} \quad$ (electrical time constant) and $\omega$ (electrical speed). After the short-circuit failure and the machine enters in the permanent regime, the $e^{-\frac{t}{\tau}} \rightarrow 0$ and the expression of short-circuit current in the (3) can be simplified to:

$$
i_{a}(t)=K \sqrt{A^{2}+B^{2}} \cos (\omega t+\varphi)
$$

where $K=\frac{M I_{A}}{L_{a}\left(\omega^{2}+(1 / \tau)^{2}\right)}, A=\omega\left(\frac{1}{\tau}+\frac{E_{a}}{M I_{A}}\right), B=\left(\omega^{2}-\frac{E_{a}}{M I_{A} \tau}\right)$ and $\varphi=\arctan (B / A)$.

With the obtained short-circuit current, the output torque $\left(T_{m}\right)$ produced by the three redundant phases and the short-circuit phase can be finally calculated as:

$$
T_{m}=\frac{1}{\Omega}\left([\boldsymbol{e}]_{A B C}^{t} \cdot[\boldsymbol{i}]_{A B C}+e_{a} i_{a}\right)
$$

where $\Omega$ is the rotor mechanical velocity, $[\boldsymbol{e}]_{A B C}$ and $[i]_{A B C}$ are respectively two $3 \times 1$ matrix of three phase EMFs and currents of the redundant star.

The simulation is based on the Simulink-MATLAB package, and the block-diagram of the control system is shown in the Fig. 4. The speed control is realized by a PI controller while the current control is realized by a hysteresis controller. Since the control strategy is not the main research aspect in this paper, thus, for simplifying the simulation and the experimental validation, we suppose that the redundant star is always supplied and the phase $a$ can be short circuited at any moment. In order to validate the simulated results, a dSPACE-based digital controller is designed and implemented to drive the dual star FSPM motor, and a DC motor is used as a charge of the system. The used motor is a 12-slots and 10-pole FSPM motor, the prototype is shown in the Fig. 5. The parameters of this machine are given in the appendix. 


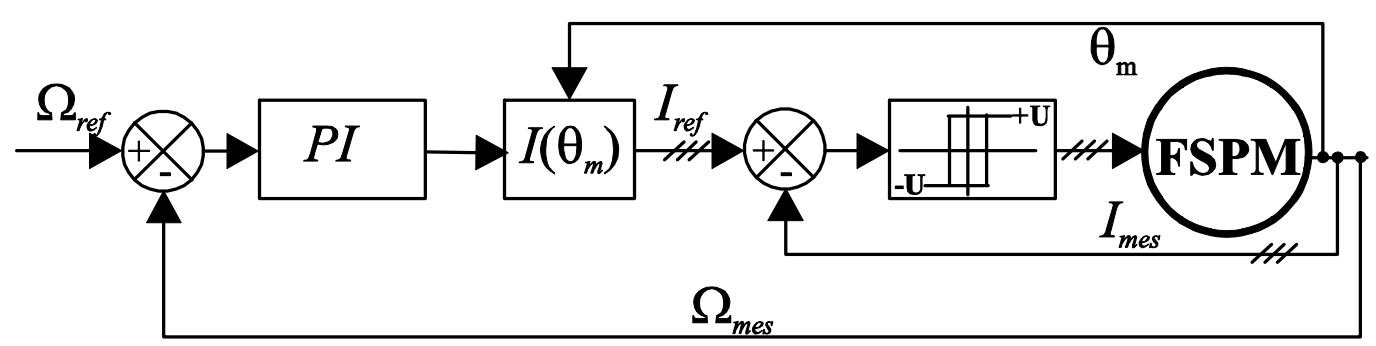

Fig. 4 Block-diagram of the control system of the dual star FSPM motor.

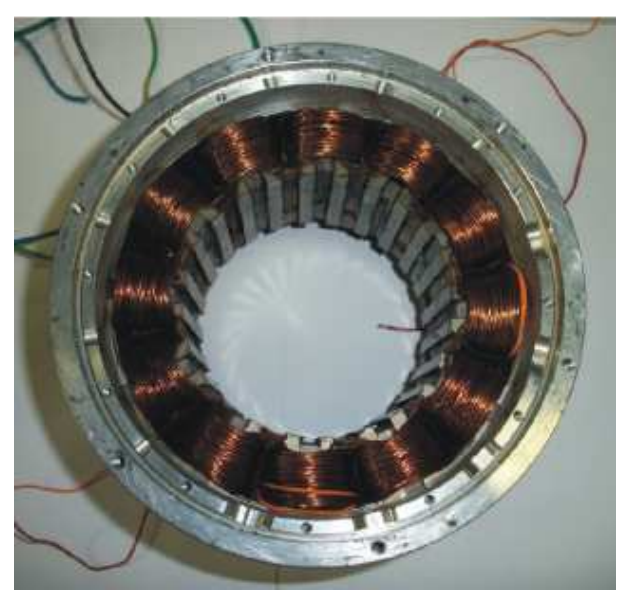

(a)

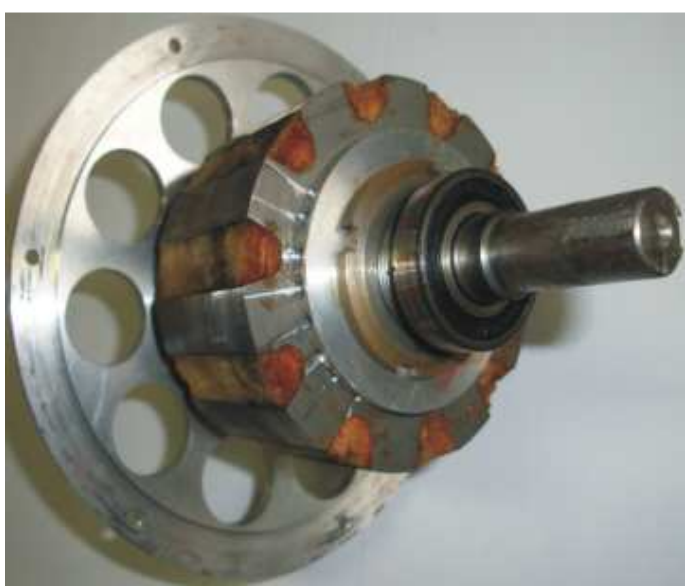

(b)

Fig. 5 Prototype of the dual star FSPM motor. (a) stator, (b) rotor.

The simulated and measured currents and rotor speeds are shown in the Fig. 6 and the Fig. 7 (SC is short-circuit). A good agreement between the simulated and measured results has been observed. When the phase $a$ is short-circuited at 2.3 seconds, a short-circuit current appears in the phase $a$, which is almost opposite to the current in the phase A. Since the EMFs of these two phases are practically identical, so, the torque produced by the short-circuit phase $a$ should also be opposite to that of the phase A (see Fig. 8). Generally, if the phase resistance, the mutual inductances and the iron losses are neglected, the short-circuit current and the phase EMF will have a phase separation of $\pi / 2$, and the average value of torque produced by the short-circuit phase will be null. However, in this paper, the angle between the short-circuit current and the phase EMF is not exactly $\pi / 2$. Thus, the value of average resistant torque due to short-circuit current is not null. On the contrary, this is always negative if we consider that the torque produced by the three redundant phases is positive. In order to maintain the same output average torque and the same 
velocity, the currents of the three phases of the redundant star should be increased to compensate the shortcircuit torque as in the Fig. 6, in which, the peak of the current has increased approximately two times.

In the Fig. 7, it is found when the short-circuit failure appears in the phase $a$, the rotor speed decreases. This is because the torque produced by the phase $a$ is always opposite to that of the phase A, which could be considered as a brake torque and decelerates the motor. However, due to the speed controller, the average speed could be maintained at the same value as the initial speed except that the speed is disturbed by the asymmetrical failure.

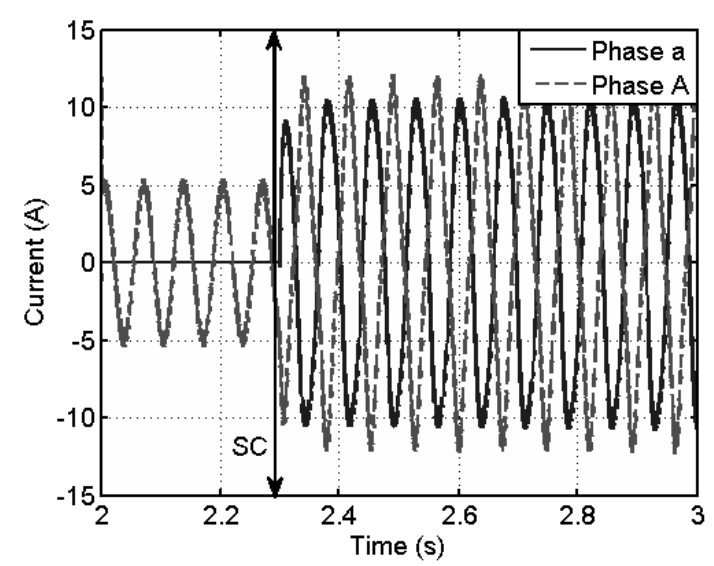

(a)

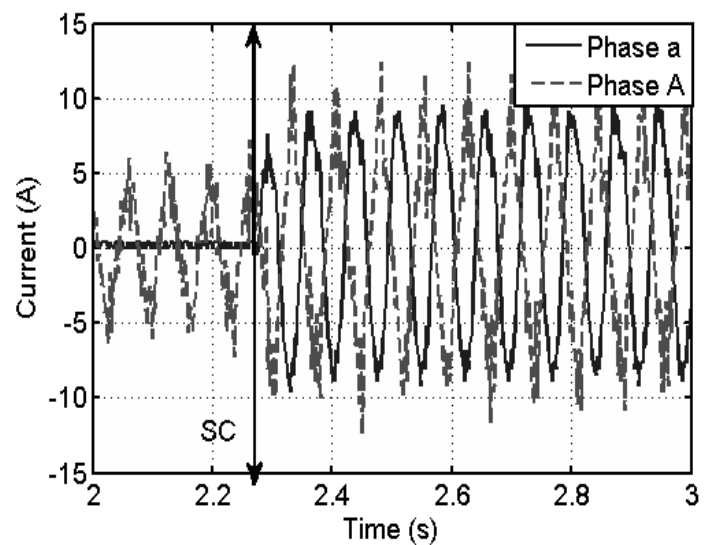

(b)

Fig. 6 Healthy and post-fault current waveforms of the healthy and short-circuit phases of the fault-tolerant dual star FSPM motor. (a) simulated results, (b) measured results.

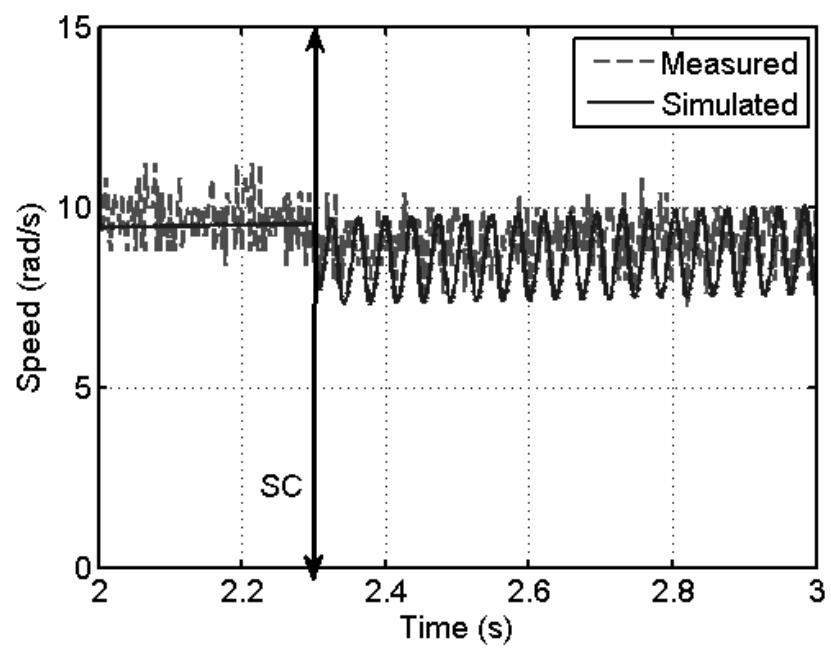

Fig. 7 Healthy and post-fault rotor mechanical velocities of the fault-tolerant dual star FSPM motor. 


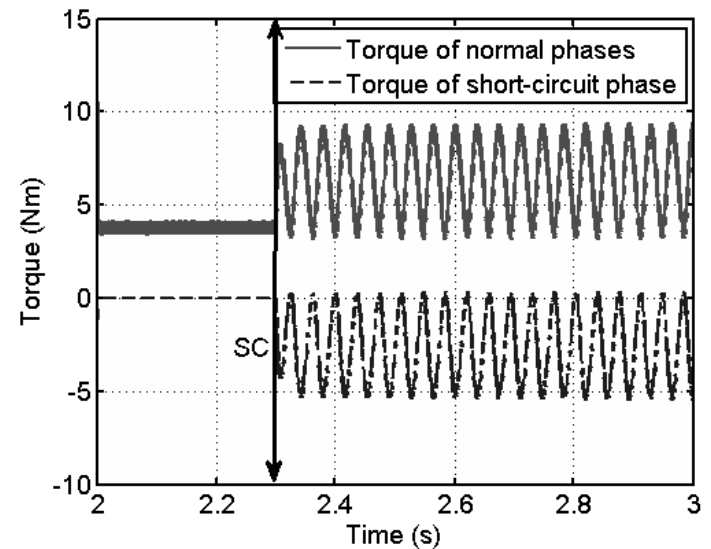

(a)

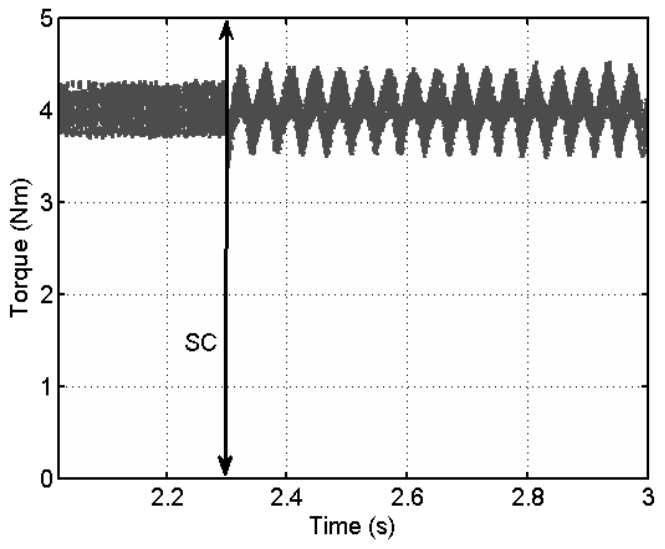

(b)

Fig. 8 Healthy and post-fault instantaneous torques of the fault-tolerant dual star FSPM motor. (a) two torque components produced by the healthy and by the short-circuit phases, (b) total torque produced by the healthy and the short-circuit phases.

The maximum short-circuit current could be predicted by the characteristic of short-circuit current versus rotor speed. The simulated and measured maximum short-circuit currents as well as that calculated analytically by the (3) are shown in the Fig. 9. It is found that the maximum short-circuit current of the dual star FSPM motor is about 20 A. At low rotor speeds, the rotor speed has a great influence on the value of short-circuit current. However, with the increase of the rotor speed, the influence of the resistance of the phase $a$ could be neglected. As a result, the short-circuit current is independent of the rotor speed at high rotor speed regions, and which could be determined by the open circuit flux and the self inductance of the phase $a$. This is why the maximum short-circuit current is approximately constant at high rotor speeds. 


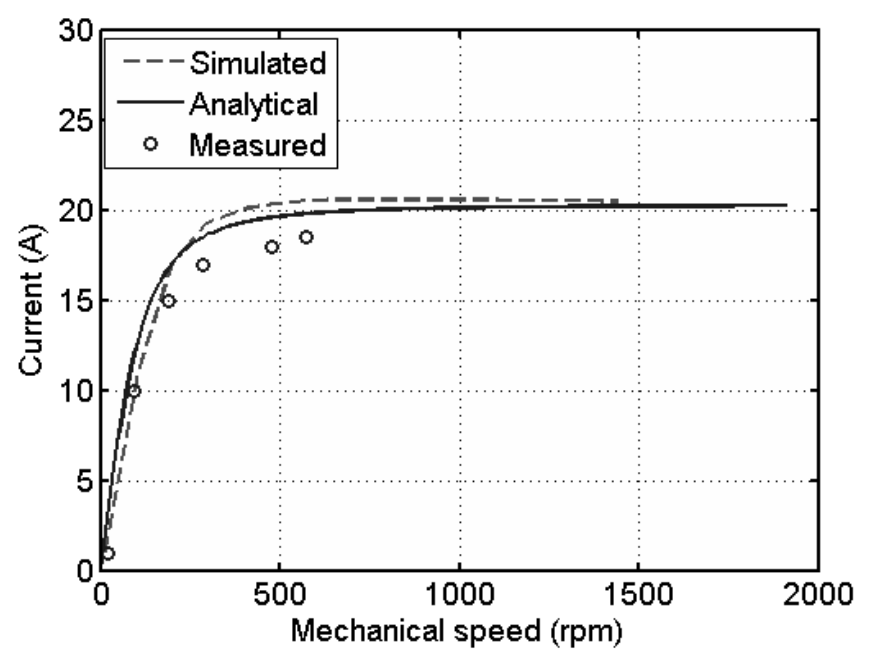

Fig. 9 Short-circuit peak current versus rotor mechanical speed of the fault-tolerant dual star FSPM motor.

\subsection{COPPER AND IRON LOSSES MODEL}

For one phase short-circuit condition, the copper losses $\left(P_{C O}\right)$ of the dual star FSPM motor depends on the phase resistance, the normal and short-circuit phase RMS currents. They can be computed as follows:

$$
P_{C O}=3 R I_{R M S}^{2}+R I_{S C}^{2}
$$

where $R$ is the phase resistance (in this paper, the resistivity of copper is considered as constant and independent of the temperature variation), $I_{R M S}$ and $I_{S C}$ are respectively the normal and short-circuit phase RMS currents. The RMS phase currents could be obtained by Simulink-MATLAB based model as shown in the Fig. 6. It is clear that the strong increase of phase currents certainly leads to a considerable increase of the copper losses, because the latter one is proportional to the square of RMS currents.

As one kind of main heat sources of the electrical machines, the stator and rotor iron losses should be calculated so as to precisely predict the temperatures of different parts of the electrical machines. The expression of stator and rotor iron loss densities $\left(P_{x}\left(W / m^{3}\right)\right)$ could be established as [23]

$$
P_{x}\left(W / m^{3}\right)=f_{x}\left(k_{h 1} \Delta B_{p p}+k_{h 2} \Delta B_{p p}^{2}\right)+k_{e} f_{x} \int_{0}^{\frac{1}{f_{x}}}\left(\frac{\partial B}{\partial t}\right)^{2} d t
$$

Where 
$f_{x}(x=R, S)$

$k_{h l}=5 \mathrm{~A} / \mathrm{m}$ and $k_{h 2}=40 \mathrm{Am} / \mathrm{Vs}$

$B_{p p}($ Tesla $)$

$k_{e}=0.022 \mathrm{Am} / \mathrm{V}$
: $\operatorname{Rotor}(R)$ or Stator $(S)$ electrical frequency,

: Hysteresis loss coefficients,

: Peak-to-Peak value of flux density,

: Eddy current loss coefficient.

In this paper, the hysteresis and eddy current loss coefficients are obtained by experimental methods.

With the instantaneous normal and short-circuit currents obtained by simulation and validated by experiments, the rotor and stator magnetic flux density versus rotor position could also be calculated by $2 \mathrm{D}$ FEM.

Table 1

Copper losses and rotor as well as stator iron losses for two driving points

\begin{tabular}{lllll}
\hline \hline & Healthy mode & \multicolumn{2}{l}{ Fault mode } \\
\hline & Point $I$ & Point $I I$ & Point $I$ & Point $I I$ \\
\hline Rotor speed (rpm) & 1000 & 100 & 1000 & 100 \\
Output torque (Nm) & 4 & 8 & 4 & 8 \\
Phase resistance ( $\Omega$ ) & 0.53 & 0.53 & 0.53 & 0.53 \\
Healthy current (A) (RMS) & 3.54 & 7.36 & 9.2 & 11 \\
Short-circuit current (A) (RMS) & 0 & 0 & 14 & 5.5 \\
Copper losses (W) (normal phases) & 19.9 & 86 & 134.6 & 192.4 \\
Copper losses (W) (short-circuit phases) & 0 & 0 & 103.9 & 16 \\
Rotor iron losses (W) & 2.5 & 0.1 & 2.6 & 0.13 \\
Stator iron losses (W) & 8.7 & 0.27 & 8.9 & 0.28 \\
\hline \hline
\end{tabular}

In this paper, two driving points are chosen such as at the driving point $I$, the output torque and the rotor velocity are respectively $4 \mathrm{Nm}$ and $1000 \mathrm{rpms}$ while at the driving point $I I$, the output torque and the rotor velocity are respectively $8 \mathrm{Nm}$ and $100 \mathrm{rpms}$. The obtained copper losses and the stator as well as rotor iron losses are shown in the Table 1. As discussed in previous sections, to maintain the same output torque in presence of one phase short-circuit, the currents of the healthy phases should be increased. Thus, together with the short-circuit current, the copper losses increase considerably comparing to healthy mode. However, in presence of short-circuit, the stator and rotor iron losses increase only slightly. 


\section{Thermal Model OF DUAL Star FSPM MOTOR}

\subsection{LUMPED-PARAMETER (LP) THERMAL MODEL}

As in power system, using the network thermal resistance to model the nodal temperature and the heat flux paths in the electrical machine is possible [13]-[15], [17], [20]-[21], [24]. Concerning this method, the different parts of machine could be modelled by different thermal resistances. Moreover, the different heat transfer mechanisms, e.g. thermal conduction, thermal convection and thermal radiation can be taken into account. The accuracy of this method depends on the discretization level of different parts of the machine. Generally, the higher is the discretization level, the higher is the accuracy, while the longer is the calculate time. Comparing to the Finite Element Analysis, the lumped-parameter $(L P)$ thermal model can have the similar accuracy of computation while with much shorter consuming time. This is the main benefit of this model, which is much more interesting for the machine optimisation that needs numerous iterations of calculate. In order to establish the $L P$ thermal model, the different thermal transfer mechanisms are detailed in the following sections.

\subsubsection{Thermal Conduction}

The general expression of temperature describing the heat transfer is

$$
-\lambda \nabla^{2} T+\rho c_{p} \frac{\partial T}{\partial t}=\dot{q}
$$

where $\lambda\left(\mathrm{W} / \mathrm{m} /{ }^{\circ} \mathrm{C}\right), \rho\left(\mathrm{kg} / \mathrm{m}^{3}\right), c_{p}\left(\mathrm{~J} / \mathrm{kg} /{ }^{\circ} \mathrm{C}\right)$ and $\dot{q}\left(\mathrm{~W} / \mathrm{m}^{3}\right)$ are thermal conductivity, density, specific heat capacity and heat source, respectively. After resolving the expression (8) in steady-state regime, the general expression of thermal resistances of different motor components $\left(R_{\text {conduction }}\left({ }^{\circ} \mathrm{C} / W\right)\right)$ representing the conductive heat transfer in one direction is [14]

$$
R_{\text {conduction }}=\frac{L}{\lambda S}
$$

where $L(m)$ and $S\left(\mathrm{~m}^{2}\right)$ are the length following the heat flow direction and the area of the cross-section of the motor component. 
Since the structure of the electrical machine in this paper is cylindrical, using two cylinders to represent different components are possible, which is shown in the Fig. 10. In zone $I\left(r_{1}<r<r_{2}\right)$, with heat sources, which represents the redundant phase windings and the short-circuit phase winding (in fault mode), the stator and the rotor iron core. While in zone $I I\left(r_{2}<r<r_{3}\right)$, without heat sources, which presents the frame, the shaft, the permanent magnets, the outer and inner air of the machine. In axial direction ( $z$ axis), the heat can be removed in $\pm z$ directions, and for simplicity, only $+z$ direction thermal resistances $\left(R_{d}\right.$ and $\left.R_{e}\right)$ are shown in the Fig. 10. Because of the irregular distribution of the coils in the stator slots, the precise thermal model of each coil is significantly difficult. Thus, as in some of previous studies [15]-[16], the stator slots are considered as an equivalent homogeneous material so as to simplify the thermal model.

The winding equivalent thermal conductivity of the prototype is obtained by analytical method (see equation (10)), and verified by Finite Element and experimental methods as in the following parts. In this paper, a value of $0.2 \mathrm{~W} / \mathrm{m} /{ }^{\circ} \mathrm{C}$ is given for a stator slots filling coefficient of $40 \%$. It should be noted that in the stator and in the rotor as well as in the phase windings, the axial thermal conductivity and the radial thermal conductivity are not the same. This is mainly due to the dielectric coating layer between the conductors (iron and copper). For example, in the laminated stator core, the radial equivalent thermal resistance is the parallel resistance of the laminations and the dielectric coating layers, which could be considered as similar to the thermal resistance of pure iron. While, in the axial direction, the equivalent thermal resistance is the series resistance of the laminations and the dielectric coating layers, which is much higher than the radial thermal resistance because the dielectric coating layers are not good thermal conductors. As a result, the radial thermal conductivity in the laminated stator or rotor is often much higher than the axial one. This is contrary to the stator winding, in which, the axial thermal conductivity is similar to that of the copper, while the radial thermal conductivity is considerably lower. This is main reason why the maximum temperature is often found in the end-windings of the electrical machines. 


$$
\lambda_{e q}=\lambda_{i} \frac{\left(1+k_{b}\right) \lambda_{c}+\left(1-k_{b}\right) \lambda_{i}}{\left(1-k_{b}\right) \lambda_{c}+\left(1+k_{b}\right) \lambda_{i}}
$$

where $\lambda_{i}\left(\mathrm{~W} / \mathrm{m} /{ }^{\circ} \mathrm{C}\right), \lambda_{c}\left(\mathrm{~W} / \mathrm{m} /{ }^{\circ} \mathrm{C}\right)$ and $k_{b}$ are respectively the thermal conductivity of isolation, the thermal conductivity of copper and the filling factor.

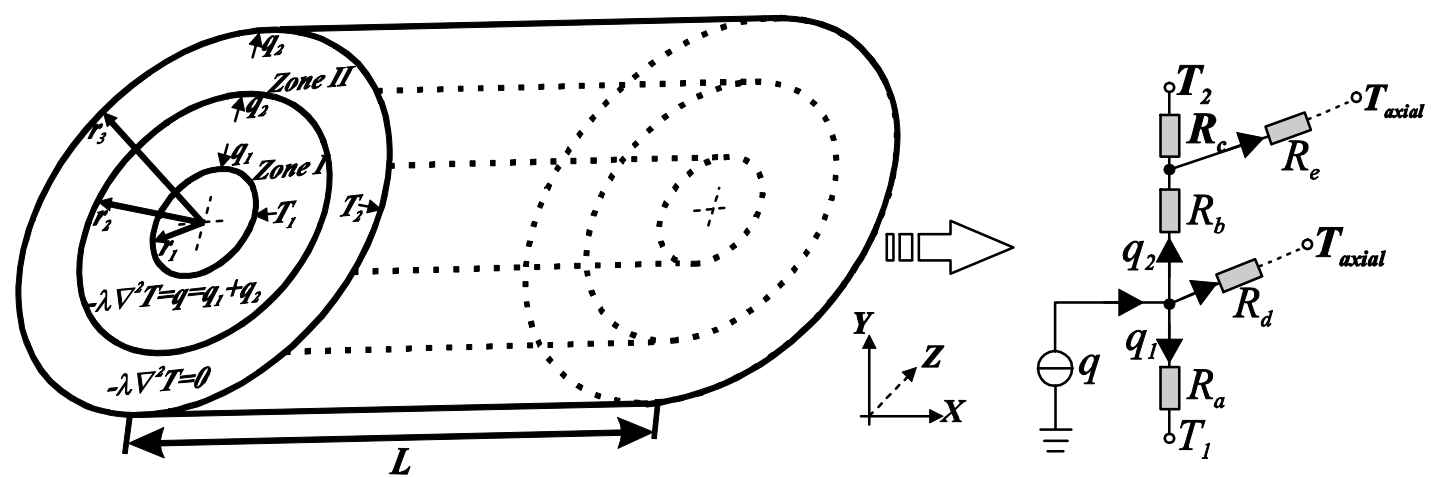

Fig. 10 Zones describing the heat transfer of different components of electrical machines, Zone I: with heat source $(q \neq 0)$, Zone II: without heat source $(q=0)$.

After resolving the different equations as shown in the Fig. 10, the thermal resistances of different components of the electrical machine in form of the expression (9) are

$$
\left\{\begin{array}{l}
R_{a}=R_{b}=\frac{1}{8 \pi \lambda L}\left(1-\frac{2 r_{1}^{2}}{r_{2}^{2}-r_{1}^{2}} \ln \left(\frac{r_{2}}{r_{1}}\right)\right) \\
R_{c}=\frac{1}{2 \pi \lambda L} \ln \left(\frac{r_{3}}{r_{2}}\right) \\
R_{d}=\frac{L}{4 \pi \lambda\left(r_{2}^{2}-r_{1}^{2}\right)} \\
R_{e}=\frac{L}{2 \pi \lambda\left(r_{3}^{2}-r_{2}^{2}\right)}
\end{array}\right.
$$

where $L(m)$ is the axial length of the cylinder in $z$ direction, $r_{1}(m), r_{2}(m)$ and $r_{3}(m)$ are the inner, the middle and the outer radii of this cylinder, respectively. The (11) could be applied to calculate the thermal resistance of all the motor components due to thermal conduction. 


\subsubsection{Thermal Convection}

In the electrical machines, the thermal convection phenomena could be divided into two categories. The first one is the external thermal convection between the outer surface of the frame and the cooling system (fluid or gas), which could be modelled as the thermal convection between a cylinder and the cooling fluid. While the thermal convection between the inner lateral surfaces of the frame and the end-windings, and the thermal convection between the stator and the rotor are included in the second category, which is the internal thermal convection within the electrical machine. All the foregoing thermal convections could be considered as between the solid surfaces and the nearby cooling fluid and modelled by a single thermal resistance $\left(R_{\text {convection }}\left({ }^{\circ} \mathrm{C} / W\right)\right)$ as

$$
R_{\text {convection }}=1 /(h S)
$$

where $h\left(\mathrm{~W} / \mathrm{m}^{2} /{ }^{\circ} \mathrm{C}\right)$ and $S\left(\mathrm{~m}^{2}\right)$ are respectively the convection coefficient and the exchange surface area between the solid surfaces and the nearby cooling fluid.

In order to obtain the convective thermal resistances in the electrical machines, the accurate calculation of the convection coefficients in different parts of the electrical machine is essential. However, it should be taken into account that the precise computation of thermal convection coefficient is a significantly demanding task. This can be performed by lots of Computational Fluid Dynamics (CFD) [16]. While the CFD calculations are very time-consuming and need a solid knowledge of mechanical fluid in air-gap. This is certainly a very challenging task in the machine conception process. Furthermore, the obtained convection coefficient of one certain machine could not be used for other machines, because the convection coefficient depends much on the motor structures.

As mentioned in previous sections, the foregoing machine is designed for a Variable Stator Vane (VSV) application. Thus, the machine should be a totally enclosed one, and the only cooling system is the ambient air flow nearby the outer surface of the frame. The convection coefficient between the external surface of the frame and the ambiance is obtained by experiments and a value as $h=30 \mathrm{~W} / \mathrm{m}^{2} /{ }^{\circ} \mathrm{C}$ is given in the 
machine specifications. The experiments is realised by using a cylinder, the outer diameter of which is similar to that of the machine. The power losses $(P(W))$ are distributed uniformly in the cylinder. The outer surface and ambient temperatures can be measured. The thermal resistance $\left(R_{\text {convection }}\right)$ due to outer surface convection can be obtained by using equation (20). Based on the expression (12), the thermal coefficient can be finally calculated. Two things should be taken into account that, the difference between the outer surface temperature and the ambient temperature must be low enough to avoid the influence of thermal radiation, and the air density should be considered constant.

Without motor fan on the rotor, the axial fluid flow in the air gap could be neglected comparing to the radial fluid flow. Furthermore, even if the air flow in the air-gap is turbulent, it could still be considered that there is a thin layer of air nearby the rotor tooth tips, which is laminar, and rotates with the rotor with the same peripheral speed of rotor tip. This is the same case for the air flow inter-rotor teeth. Thus, the convection coefficient in the air-gap could then be calculated as follows [14], [16]

$$
T a=\frac{\rho^{2} \Omega^{2} r_{a} e^{3}}{\mu^{2}}
$$

Where

$\mathrm{Ta}$

: Taylor number,

$\mu(\mathrm{Pa} \cdot \mathrm{s}) \quad$ : Dynamic viscosity of fluid in air-gap,

$\Omega(\mathrm{rad} / \mathrm{s}) \quad$ : Rotor mechanical speed,

$r_{a}=e / \ln \left(\frac{r_{s_{\_} \text {inner }}}{r_{r_{-} \text {outer }}}\right):$ Mean logarithmic radius,

$e(m) \quad: \quad$ Air-gap length,

$r_{S_{-} \text {inner }}(m) \quad: \quad$ Stator inner radius,

$r_{r_{-} \text {outer }}(m) \quad: \quad$ Rotor outer radius.

Based on the obtained Taylor number, the Nusselt number $(\mathrm{Nu})$ can then be calculated as 


$$
\begin{cases}N u=2 & (T a<1708) \\ N u=0.128 T a^{0.367} & (1800<T a<12000) \\ N u=0.409 T a^{0.241} & \left(12000<T a<4.10^{6}\right)\end{cases}
$$

The convection coefficient could finally be established as

$$
h=\frac{N u \cdot \lambda}{D_{h}}
$$

where $D_{h}(m)$ is the hydraulic diameter, which is equal to two times the air-gap length $(2 \times e)$ for the electrical machines with narrow air-gap. Using the expression (12), the thermal resistance due to thermal convection in the air-gap could be obtained.

Concerning the end-windings, without the motor fan on the rotor, the thermal convection around the endwindings could be considered as natural, and the thermal convection for the vertical plate surface could be applied for computing the Nusselt number as [24]

$$
N u=\left(0.825+0.387 R a_{D}^{0.166}\left(1+0.671 P r^{-0.5625}\right)^{-0.296}\right)^{2}
$$

where $R a_{D}$ and $\operatorname{Pr}$ are respectively the Rayleigh number and the Prandtl number. This can also be used for calculating the Nusselt number of the inner lateral surface of the frame. However, for the lateral surface of the rotor, the thermal convection is forced, and the Nusselt number should be calculated as follows [25]

$$
\left\{\begin{array}{l}
N u_{D}=0.664 R e_{D}^{0.5} \operatorname{Pr}^{0.333}\left(\operatorname{Re}_{D}<500000\right) \\
N u_{D}=\left(0.037 \operatorname{Re}_{D}^{0.8}-871\right) \operatorname{Pr}^{0.333}\left(\operatorname{Re}_{D} \geq 500000\right)
\end{array}\right.
$$

where the $R e_{D}$ is the Reynolds number.

\subsubsection{Thermal radiation}

Within the electrical machines, because of the relatively low temperature gradients between different parts, the thermal radiation is often not as important as the thermal conduction as well as the thermal convection [14]. Generally, the higher the temperature difference between the surfaces of the machine, the higher the heat flow transferred by the thermal radiation. In electrical machines, the thermal radiation could also be divided into two categories as the same way for modelling the thermal convection. The first one is between the surface and the surrounding environment, e.g. the extern surface of frame and the ambient. The 
second one is between two surfaces, e.g. the rotor outer surface and the stator inner surface (air-gap), the end-windings and the inner lateral surface of the frame (cavity), etc. As mentioned previously, the second one is often neglected, and only the first one is taken into account. If the ambient surrounding the outer surface of the frame is great enough to be considered as a blackbody, then the surface radiation transfer $\left(q_{\text {rad }}\right)$ between the surface and the ambient could be established as [14]

$$
q_{\text {rad }}=\varepsilon_{t h} \sigma_{S B}\left(T_{s}^{4}-T_{a}^{4}\right)
$$

Where

$\varepsilon_{t h}:$ Total surface emissivity,

$\sigma_{S B}:$ Stefan-Boltzmann constant,

$T_{S}:$ Surface temperature in degree,

$T_{a}:$ Ambient temperature in degree.

Using the same way as for modelling the thermal convection, the thermal resistance due to radiation could be established as

$$
R_{\text {radiation }}=\frac{T_{S}-T_{a}}{q_{\text {rad }} \cdot S}
$$

Using the motor parameters shown in appendix, the thermal resistances of different motor components due to thermal conduction can be calculated with the method as in paragraph 3.1.1, and thermal convection and thermal radiation could be obtained by the methods presented in paragraphs 3.1 .2 and 3.1.3. After a series of calculations, the complete Lumped Parameter $(L P)$ thermal model of the dual star FSPM motor is then established, and shown in the Fig. 11. The different thermal resistances are described as in the Table 2. 


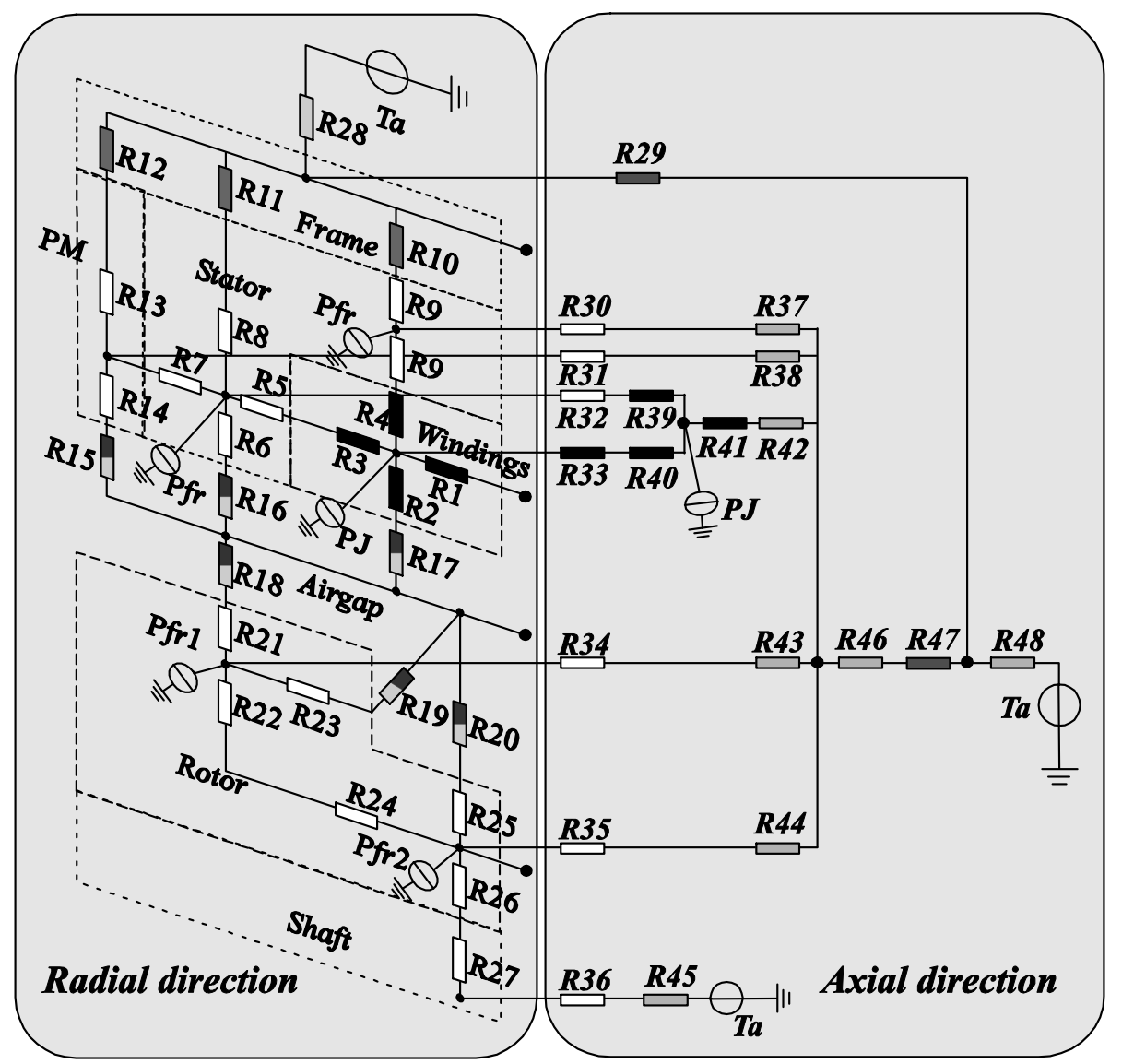

Fig. 11 Lumped-Parameter steady state thermal model of the dual star FSPM motor.

Table 2

Thermal resistances of different parts of the dual star FSPM motor

\begin{tabular}{lll}
\hline \hline & Radial direction & Axial direction \\
\hline Stator slots & $R 1-R 4$ & $R 33$ \\
Stator tooth & $R 5-R 8$ & $R 32$ \\
Stator yoke & $R 9$ & $R 30$ \\
Frame & $R 10-R 12$ & $R 29, R 47$ \\
Permanent magnet & $R 13-R 14$ & $R 31$ \\
End-winding & $R 39, R 41$ & $R 40$ \\
Rotor tooth & $R 21-R 23$ & $R 34$ \\
Rotor yoke & $R 24-R 26$ & $R 35$ \\
Shift & $R 27$ & $R 36$ \\
Air-gap & $R 15-R 20$ & - \\
Cavity of end-wing & - & $R 37-R 38, R 42-R 44, R 46$ \\
Frame surface & $R 28$ & $R 48$ \\
\hline \hline
\end{tabular}

Based on the thermal network shown in the Fig. 11, a relationship among the thermal conductances, the node temperature and the node power losses can be finally established as 


$$
\left[\begin{array}{cccc}
Y_{11} & Y_{12} & \cdots & Y_{1 n} \\
Y_{21} & Y_{22} & \ddots & Y_{2 n} \\
\vdots & \vdots & \cdots & \vdots \\
Y_{n 1} & Y_{n 1} & \cdots & Y_{n n}
\end{array}\right]\left[\begin{array}{c}
T_{1} \\
T_{2} \\
\vdots \\
T_{n}
\end{array}\right]=\left[\begin{array}{c}
P_{1} \\
P_{2} \\
\vdots \\
P_{n}
\end{array}\right]
$$

Where $[\boldsymbol{T}]_{n \times \mathbf{1}}$ is the node temperature matrix, $[\boldsymbol{P}]_{\boldsymbol{n} \times \mathbf{1}}$ is the node power loss matrix, $[\boldsymbol{Y}]_{\boldsymbol{n} \times \boldsymbol{n}}$ is the thermal conductance matrix.

\subsection{D FEM THERMAL MODEL}

Different from the non-salient electrical machines, the steady state thermal model at one rotor position is not suitable for the doubly salient machines as longer. However, it is always possible to transform the salient rotor into a non-salient one. Since the thermal time constant is much longer than the mechanical period of dual star FSPM motor, so, the air at the middle of air-gap could be heated up uniformly by the rotor tooth tip or the air inter-rotor teeth. As a result, it could be considered that the air layer in the middle of air-gap is isothermal. Moreover, since there is a fin layer of air nearby the rotor tooth tip, which rotates with the rotor with the same peripheral velocity. Thus, to the immobile part of stator, the rotating rotor part (the mobile rotor and the half of air-gap nearby the rotor) could be considered as an equivalent homogeneous material, and which is immobile. The equivalent radial thermal resistance of the rotor could be obtained as in the Fig. 12.

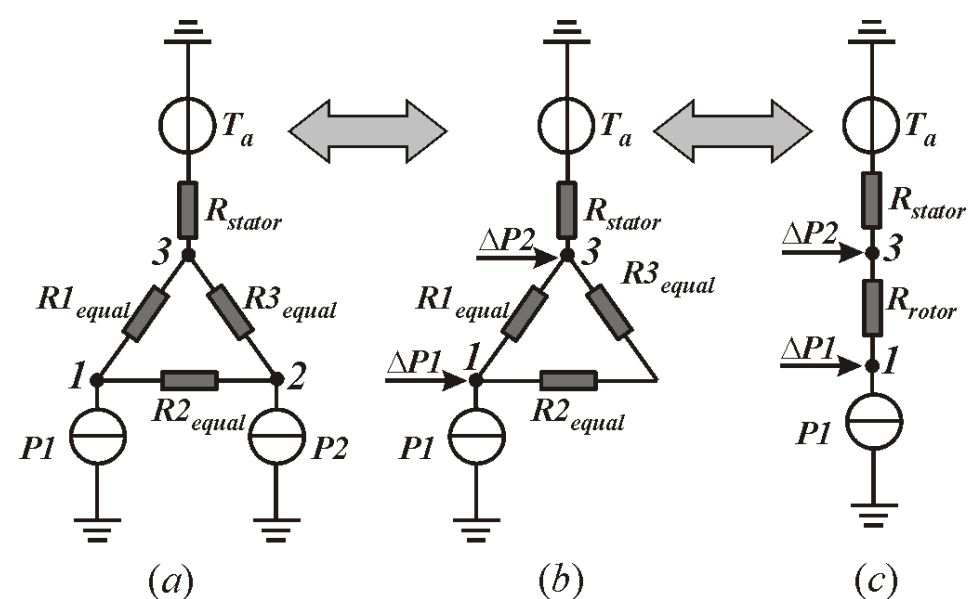

Fig. 12 Procedure of calculating the equivalent rotor thermal resistance of the fault-tolerant dual star FSPM motor. 
In the Fig. 12, for simplicity, the stator part is replaced by only one thermal resistance $\left(R_{\text {stator }}\right) . T_{a}\left(22^{\circ} \mathrm{C}\right.$ in this paper) is the ambient temperature, $P 1$ and $P 2$ are respectively the iron losses $P_{f r 1}$ and $P_{f r 2}$ in the rotor. The different components in the Fig. 12 (a) and (b) can be obtained using the network of the Fig. 11 as

$$
\begin{gathered}
\left\{\begin{array}{l}
R 1_{\text {equal }}=\frac{(R 18+R 21) \cdot(R 23+R 19)}{R 18+R 21+R 23+R 19} \\
R 2_{\text {equal }}=R 22+R 24 \\
R 3_{\text {equal }}=R 20+R 25
\end{array}\right. \\
\left\{\begin{array}{l}
\Delta P 1=R 3_{\text {equal }} \cdot P 2 /\left(R 2_{\text {equal }}+R 3_{\text {equal }}\right) \\
\Delta P 2=R 2_{\text {equal }} \cdot P 2 /\left(R 2_{\text {equal }}+R 3_{\text {equal }}\right)
\end{array}\right.
\end{gathered}
$$

The rotor part equivalent thermal resistance $\left(R_{\text {rotor }}\right)$ in the Fig. 12 (c) could then be obtained as

$$
R_{\text {rotor }}=\frac{\left(R 3_{\text {equal }}+R 2_{\text {equal }}\right) \cdot R 1_{\text {equal }}}{\left(R 1_{\text {equal }}+R 2_{\text {equal }}+R 3_{\text {equal }}\right)}
$$

With the expression (11), the equivalent radial thermal conductivity of the equivalent rotor could be finally obtained. Concerning the axial thermal conductivity, which is approximately equal to the axial thermal conductivity of the laminated rotor.

The results of temperatures obtained by $L P$ model and by 3D FEM for the driving point $I I$ are shown in the Table 3. It is found that, the highest temperature is always at the normal phase end-winding in both the healthy mode and the fault mode. However, the lowest temperature is at the lateral surface of the frame. It is also important to note that the temperature prediction for the critical application as in this paper is necessary during the preliminar conception, because a disign in the normal mode could not satisfy the thermal constrants in fault mode. As shown in the Table 3, the maximum temperature in fault mode is up to $148^{\circ} \mathrm{C}$. If the rotor speed increases, the temperature could exceed the thermal constraints and damage the winding isolations.

The temperature distributions of the dual star FSPM motor in normal and fault modes at driving point $I I$ are shown in the Fig. 13. To some degrees, at driving point $I I$ and in fault mode, the maximum temperature 
of the end-winding is so high that the windings isolated material could be damaged. In order to decrease the maximum temperature of the electrical machine, the minimisation of the power losses is always a good choice, while enhancing the performance of cooling system is also a good alternative. In the cavity around the end-windings, the rotor mounted fan (Totally Enclosed Fan Cooled (TEFC) structure) could be applied to increase the air circulation. While on external surface of the frame, several kinds of cooling fins could be applied to increase the heat exchange area. To evaluate the heat transfer on a finned surface cooled by air, some methods have been proposed in [18].

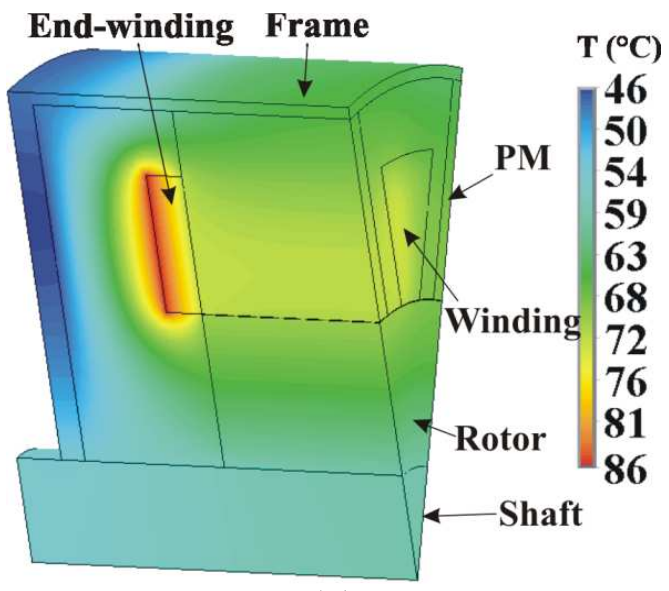

(a)

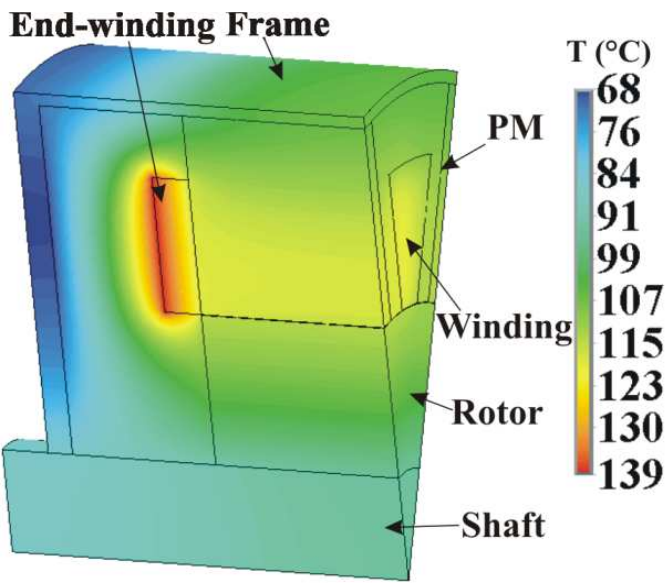

(b)

Fig. 13 Healthy and post-fault temperature distributions of the fault-tolerant dual star FSPM motor at driving point II (3D FEM results). (a) healthy mode, (b) fault mode.

\subsection{EXPERIMENTAL VALIDATION}

In order to measure the temperatures of the fault-tolerant dual star FSPM motor, a Fluke Ti20 Thermal Imager camera is used, which has an accuracy of $\pm 2^{\circ} \mathrm{C}$, and the temperature range is from $-10^{\circ} \mathrm{C}$ to $350^{\circ} \mathrm{C}$. As mentioned in previous sections, the maximum temperature is often at the end-windings. Thus, so as to display the maximum temperature by the thermal camera, some holes are punched at the end-shield and the end-shield is drawn black as shown in the Fig. 14. To avoid the influence of the thermal time constant, the image is taken when the regime of the electrical machine is permanent, i.e. after the short-circuit failure in one phase, when the temperatures are nearly stable, the machine could be considered as entering into the permanent regime. The temperature distribution at the end-windings obtained by the thermal imager 
camera is shown in the Fig. 15 . The ambient temperature is about $22^{\circ} \mathrm{C}$. In normal mode, the maximum end-winding temperature is about $95^{\circ} \mathrm{C}$. While in fault mode, the maximum temperature is about $151{ }^{\circ} \mathrm{C}$. The minimum temperatures are at the end-shield in normal mode as well as in fault mode, the values of which are respectively $49^{\circ} \mathrm{C}$ and $70^{\circ} \mathrm{C}$.

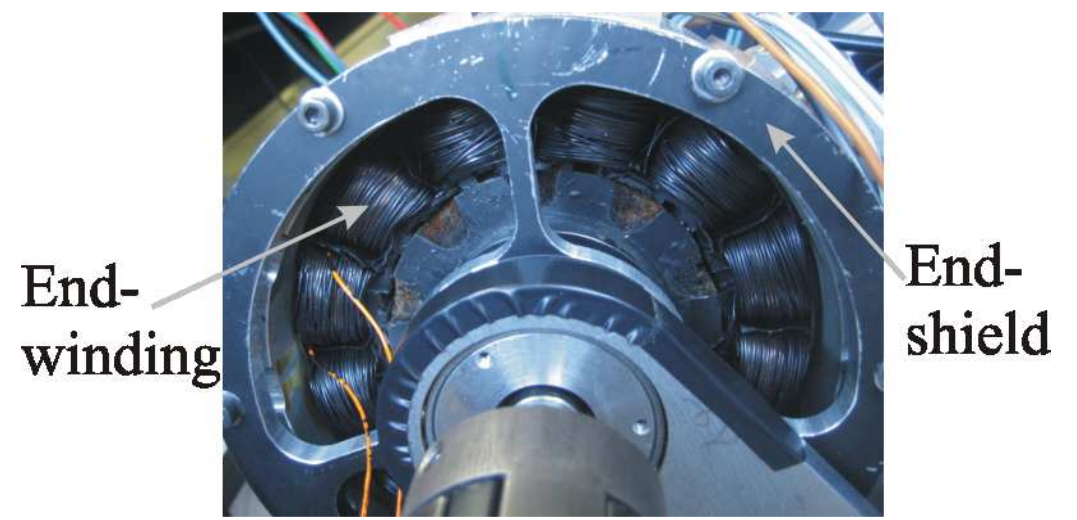

Fig. 14 Structure of the fault-tolerant dual star FSPM motor for thermal experiments

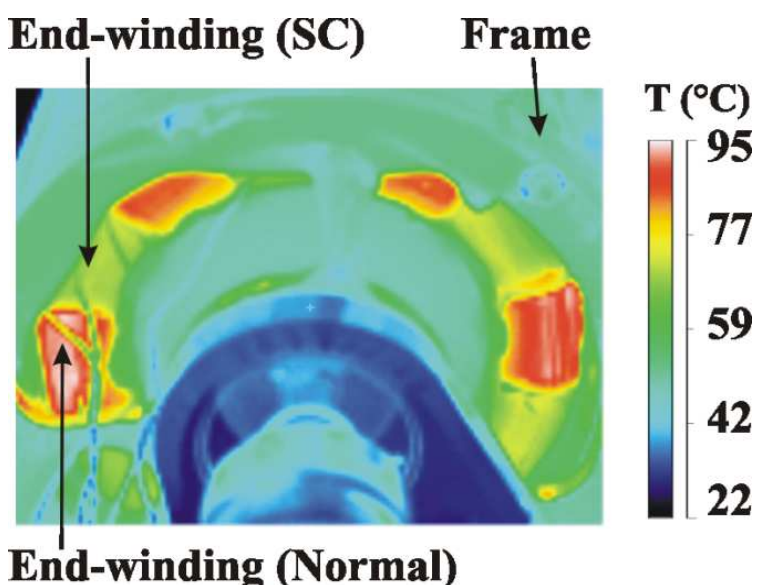

(a)

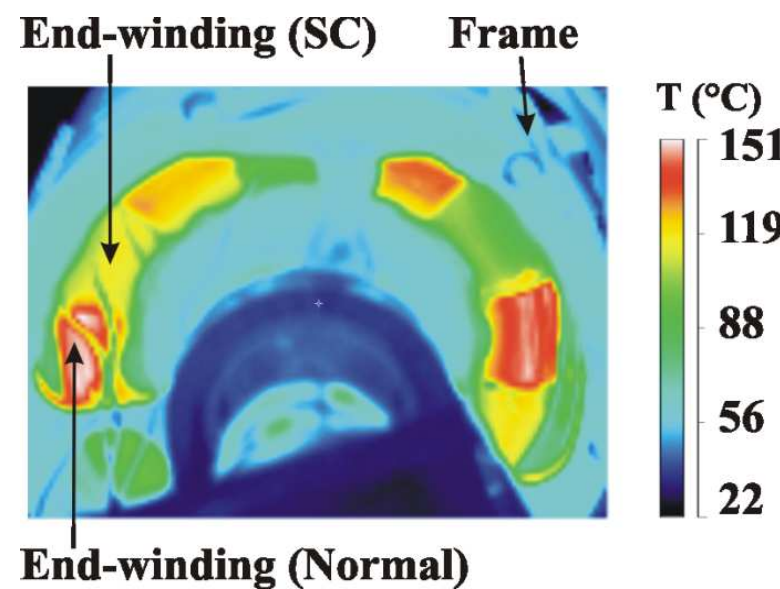

(b)

Fig. 15 Healthy and post-fault temperature distributions of the fault-tolerant dual star FSPM motor at driving point I (Experimental results). (a) healthy mode, (b) fault mode.

Table 3 Analytical, Numerical and measured Results of Temperatures at Different Locations of the Dual Star FSPM Motor in Degree Celsius $\left({ }^{\circ} \mathrm{C}\right)$

\begin{tabular}{lcccccc}
\hline & \multicolumn{3}{c}{ Healthy mode } & \multicolumn{3}{c}{ Fault mode } \\
\hline \multicolumn{1}{c}{ Location } & $L P$ model & 3D FEM & Measured & LP model & 3D FEM & Measured \\
\hline End-winding (normal phase) & 94 & 86 & 95 & 148 & 139 & 151 \\
End-winding (sc phase) & 66 & 68 & 70 & 119 & 115 & 121 \\
Minimum temperature (Frame) & 48 & 46 & 50 & 70 & 68 & 72 \\
\hline \hline
\end{tabular}




\section{Conclusion}

A short-circuit fault model of a dual star Flux-Switching Permanent Magnet (FSPM) motor has been presented. Based on this model, the short-circuit current as well as the normal currents, the rotor speed and the output torque are firstly calculated and then verified by experiments. With the obtained short-circuit and normal phase currents, the 2D FEM is used to calculate the copper and iron losses in the stator as well as in the rotor. To maintain the same output torque and the same rotor velocity as those in normal mode, the copper losses have increased considerably while the iron losses increased only slightly because of the shortcircuit current.

In order to predict the temperature increase in short-circuit mode, a lumped-parameter $(L P)$ thermal model has been established. The obtained copper and iron losses are used as heat sources to calculate the temperatures at different motor components. The accuracy of the $L P$ thermal model is finally validated by $3 \mathrm{D}$ FEM thermal model as well as experimental tests. The $L P$ and the $3 \mathrm{D}$ FEM thermal models can also be extended to cover transient problems with the thermal capacitances of different machine components.

\section{APPENDIX}

\section{STRUCTURAL DATA OF FSPM MOTOR 12/10 (PROTOTYPE)}

\begin{tabular}{ll}
\hline Number of stator/rotor poles $\left(N_{s} / N_{r}\right)$ & $12 / 10$ \\
Stator outer radius $\left(r_{s_{-} \text {outer }}\right)$ & $77.2 \mathrm{~mm}$ \\
Rotor outer radius $\left(r_{r_{-} \text {outer }}\right)$ & $43 \mathrm{~mm}$ \\
Stack length $\left(L_{a}\right)$ & $60 \mathrm{~mm}$ \\
Air-gap length $(e)$ & $0.2 \mathrm{~mm}$ \\
Number of phase coils $(N)$ & 50 \\
Filling factor $\left(k_{b}\right)$ & 0.4 \\
Remanent flux density $(B r)\left(200^{\circ} \mathrm{C}\right)$ & $0.8 \mathrm{~T}$ \\
Self inductance $\left(L_{0}\right)$ & $2.6 \mathrm{mH}$ \\
Mutual inductance $\left(M_{0}\right)$ & $1.02 \mathrm{mH}$ \\
No-load phase flux $\left(\Phi_{0}\right)$ & $51 \mathrm{mWb}$ \\
Moment of inertia $(J)$ & $1.8 \times 10^{-3} \mathrm{~kg} \cdot \mathrm{m}^{2}$ \\
Coefficient of friction $(f)$ & $20 \times 10^{-6} \mathrm{Nm} \cdot \mathrm{s}$ \\
\hline \hline
\end{tabular}


THERMAL PARAMETERS OF FSPM MOTOR 12/10 (PROTOTYPE)

\begin{tabular}{lcc}
\hline \hline & Radial conductivity $\left(\mathrm{W} / \mathrm{m} /{ }^{\circ} \mathrm{C}\right)$ & Axial conductivity $\left(\mathrm{W} / \mathrm{m} /{ }^{\circ} \mathrm{C}\right)$ \\
\hline \hline Equivalent winding & 0.2 & 300 \\
Stator iron & 5.9 & 30 \\
Equivalent rotor & 2.2 & 30 \\
Air-gap & 0.03 & 0.03 \\
Permanent magnet & 4 & 4 \\
Shaft & 51.2 & 51.2 \\
\hline \hline
\end{tabular}

\section{REFERENCES}

[1] Levi, E.: 'Multiphase Electric Machines for Variable-Speed Applications', IEEE Trans. Ind. Electron., 2008, 5, 55(5), p. 1893-1909.

[2] Williamson, S., and Smith, S.: 'Fault tolerance in multiphase propulsion motors', J. Marine Eng. Technol., 2004, (44), p. 3-7.

[3] Wang, J., Atallah, K., and Howe, D.: 'Optimal torque control of fault-tolerant permanent magnet brushless machines', INTERMAG Magnetics Conference, 2003.

[4] Bianchi, N., Bolognani. S., and Pré M. D.: 'Impact of Stator Winding of a Five-Phase PermanentMagnet Motor on Postfault Operations', IEEE Trans. Ind. Electron., 2008, 5, 55(5), p. 1978-1987.

[5] Fu, J., and Lipo, T. A.: 'Disturbance-Free Operation of a Multiphase Current-Regulated Motor Drive with an Opened Phase', IEEE Trans. Ind Appl., 1994, 9/10, 30(5), p. 1267-1274.

[6] Del Pizzo, A., Iannuzzi, D., and Spina, I.: 'High Performance Control Technique forUnbalanced Operations of Single-VSI Dual PM Brushless Motor Drives', IEEE international symposium on industrial electronics (ISIE), 2010, Bari, Italy, p. 1302-1307.

[7] Shamsi-Nejad, M., Nahid-Mobarakeh B., and Pierfederici, S.: 'Fault tolerant and minimum loss control of double- star synchronous', IEEE Trans. Ind. Electron., 2008, 5, 55(5), p. 1956-1965.

[8] Takorabet, N., Caron, J. P., Vaseghi, B., Nahid-Mobarakeh, B., Meibody-Tabar, F., and Humbert, G.: 'Study of Different Architectures of Fault Tolerant Actuator Using a Double-Star PM Motor', IEEE Industry Applications Society Annual Meeting, IAS'08, 2008.

[9] Ertugrul, N., Soong, W., Dostal, G., and Saxon, D.: 'Fault tolerant motor drive system with redundancy for critical applications', IEEE 33rd Annual Power Electronics Specialists Conference, 2002, p. 1457- 1462.

[10] Zhu, Z. Q., Pang, Y., Howe, D., Iwasaki, S., Deodhar, R., and Pride, A.: 'Analysis of electromagnetic performance of flux-switching permanent magnet machines by non-linear adaptive lumped parameter magnetic circuit model', IEEE Trans. Magn., 2005, 11, 41(11), p. 4277-4287.

[11] Hoang, E., Ben-Ahmed, H., and Lucidarme, J.: 'Switching flux permanent magnet polyphased synchronous machines', Proc. 7th Eur. Conf. Power Electron. Appl.,1997, p. 903-908.

[12] Vong, P., and Rodger, D.: 'Coupled Electromagnetic-Thermal Modeling of Electrical Machines', IEEE Trans. Magn., 2003, 5, 39(3), p. 1614-1617.

[13] Alberti, L., and Bianchi, N.: 'A Coupled Thermal-Electromagnetic Analysis for a Rapid and Accurate Prediction of IM Performance', IEEE Trans. Ind. Electron., 2008, 10, 55(10), p. 35753582.

[14] Nerg, J., Rilla, M., and Pyrhönen, J.: 'Thermal Analysis of Radial-Flux Electrical Machines With a High Power Density', IEEE Trans. Ind. Electron., 2008, 10, 55(10), p. 3543-3554.

[15] EL-Refaie, A. M., Harris, N. C., Jahns, T. M., and Rahman, K. M.: 'Thermal Analysis of Multibarrier Interior PM Synchronous Machine Using Lumped Parameter Model', IEEE Trans. Energy Convers., 2004, 6, 19(2), p. 303-309. 
[16] Trigeol, J. F., Bertin, Y., and Lagonotte, P.: 'Thermal Modeling of an Induction Machine Through the Association of Two Numerical Approaches', IEEE Trans. Energy Convers., 2006, 6, 21(2), p. 314-323.

[17] Cavagnino, A., Staton, D., Shanel, M., Mueller, M., Boglietti, A., and Mejuto, C.: 'Evolution and Modern Approaches for Thermal Analysis of Electrical Machines', IEEE Trans. Ind. Electron., 2009, 3, 56(3), p. 871-882.

[18] Valenzuela, M. A., and Tapia, J. A.: 'Heat transfer and thermal design of finned frames for TEFC variable-speed motors', IEEE Trans. Ind. Electron., 2008, 10, 55(10), p. 3500-3508.

[19] Micallef, C., Pickering, S. J., Simmons, K. A., and Bradley, K. J.: 'Improved cooling in the end region of a strip-wound totally enclosed fan-cooled induction electric machine', IEEE Trans. Ind. Electron., 2008, 10, 55(10), p. 3517-3524.

[20] Dorrell, D. G.: 'Combined Thermal and Electromagnetic Analysis of Permanent-Magnet and Induction Machines to Aid Calculation', IEEE Trans. Ind. Electron., 2008, 10, 55(10), p. 35663574.

[21] Momen, M. F., and Husain, I.: 'Design and Performance Analysis of a Switched Reluctance Motor for Low Duty Cycle Operation', IEEE Trans. Ind. Appl., 2005, 9/10, 41(6), p. 1612-1618.

[22] Srinivas, K. N., and Arumugam, R.: 'Analysis and Characterization of Switched Reluctance Motors: Part II-Flow, Thermal, and Vibration Analyses', IEEE Trans. Magn., 2005, 4, 41(4), p. 1321-1332.

[23] Ionel, D. M., Popescu, M., McGilp, M. I., Miller, T. J. E., Dellinger, S. J., and Heideman, R. J.: 'Computation of core losses in electrical machines using improved models for laminated steel', IEEE Trans. Ind. Appl., 2007, 11/12, 43(6), p. 1544-1564.

[24] Rouhani, H., Lucas, C., and Faiz, J.: 'Lumped thermal model for switched reluctance motor applied to mechanical design optimization', Journal of Mathematical and Computer Modelling., 2007, 3, 45(5-6), p. 625-638.

[25] Incropera, F. P., and Dewitt, D. P.: 'Introduction to Heat Transfer' (John Wiley\&Sons, 2002, $5^{\text {th }}$ edn.) 